\title{
Effect of Pre-operative Amiodarone on Atrial Fibrillation after Off-Pump Coronary Artery Bypass Surgery
}

\author{
AK M Manzurul Alam¹, Istiaq Ahmed², Manzil Ahmad ${ }^{3}$, Abdullah Al Mamun Hossain ${ }^{4}$, Md. Mohashin Reza ${ }^{4}$, \\ Mizanur Rahman ${ }^{4}$, Muzibur Rahman Rony ${ }^{4}$, S M Parvez Ahmed ${ }^{4}$
}

\begin{abstract}
:
Background: Atrial Fibrillation (AF) is common in early recovery period after cardio-thoracic surgery. There have been several pharmacological and nonpharmacological strategies suggested for prevention against AF after coronary artery bypass grafting. The purpose of this study was to evaluate the effect of oral amiodarone in the prevention of atrial fibrillation in patients who underwent off pump coronary artery bypass graft (OPCAB).
\end{abstract}

Methods: This interventional study was conducted from February 2017 to January 2018 in the department of cardiac surgery, National Institute of Cardiovascular Disease (NICVD) Dhaka, Bangladesh. By purposive sampling a total of 100 patients having sinus rhythm who will undergo OPCAB were selected for the study. Among them 50 patients (Group-A) got amiodarone $(600 \mathrm{mg} /$ day started 3 days prior to surgery) and 50 patients (Group-B) did not get amiodarone. Two (2) patients of group-A were excluded from the study due to conversion to on pump from off pump during operation. So, finally group A had 48 patients and group$B$ had 50 patients. Preoperative electrocardiography (ECG), serum electrolytes (e.g. potassium \& magnesium), thyroid function test, liver function test and echocardiogram were done in all patients under study. Per-operative occurrence of AF was assessed on operation theatre monitor. Each patient was evaluated by continuous ECG up to 5 th post-operative day (POD). Serum potassium \& magnesium were measured in every alternative day up to 5th POD. ECG with long lead tracing was done for all patients on the day of hospital discharge \& was recorded. Data were analyzed by SPSS 24.0 (Statistical Package for the Social Sciences) and tested by student T-test and Chi-square test. $P<0.05$ was considered significant.

Results: Pre-operative baseline characteristics were similar in both groups. Per-operative and postoperative AF occurred more frequently in group $B$ than group A. Those were $10(20.83 \%)$ and $32(64.0 \%)$ peroperative, $9(18.75 \%)$ and $31(36.0 \%)$ immediate postoperative period respectively in group $A$ and group $B$. The result was statistically significant $(P$ value $<.05)$. Post-operative amiodarone used in all patients who developed AF irrespective of groups. This also decreased AF significantly. There were statistically no significant difference found in postoperative serum electrolytes and use of inotropes, anti-arrhythmic drugs. All patients recovered well.

Conclusion: This study concluded that preoperative oral administration of amiodarone can prevent the occurrence of atrial fibrillation in patients undergone Off Pump Coronary Artery Bypass (OPCAB).

Key wards: Amiodarone, Postoperative atrial fibrillation,
Introduction:

Atrial tachyarrhythmias are common during early recovery after cardiothoracic surgery, occurring with a frequency ranging from $10 \%$ to $30 \%{ }^{1,2}$. Atrial fibrillation (AF) often occurs in patients after both conventional and off-pump

1. Professor cardiac surgery, National Institute of Cardiovascular Disease, Dhaka, Bangladesh

2. Associate Professor, cardiac surgery, National Institute of Cardiovascular Disease, Dhaka, Bangladesh

3. Associate Professor, cardiac surgery, National Institute of Cardiovascular Disease, Dhaka, Bangladesh

4. Post graduate fellow, Cardiac surgery, National Institute of Cardiovascular Disease, Dhaka, Bangladesh Address of Correspondence: Prof. AKM Manzurul Alam, Professor Cardiac Surgery, National Institute of Cardiovascular Disease (NICVD) Dhaka, Bangladesh. Mobile: 01711533223, Email: dr.manzurs@yahoo.com,

DOI: http://dx.doi.org/10.3329/bhj.v33i1.37028

Copyright $\odot 2017$ Bangladesh Cardiac Society. Published by Bangladesh Cardiac Society. This is an Open Access articles published under the Creative Commons Attribution-NonCommercial 4.0 International License (CC BY-NC). This license permits use, distribution and reproduction in any medium, provided the original work is properly cited and is not used for commercial purposes. 
Coronary Artery Bypass Graft (OPCAB) $)^{3,2}$. AF after OPCAB most often develops between the second and fifth postoperative day with a peak incidence in the 2 nd to 3 rd postoperative days ${ }^{1}$

The incidence is mainly dependent on the type of operation as well as on patient characteristics. As the population is aging and number of cardiac surgical operations is increasing, incidence of AF has gradually increased recently. Moreover, AF brings about several problems, including hemodynamic derangement, thromboembolic complications, longer time of hospital stay, and higher costs. ${ }^{3}$

There have been several pharmacological and nonpharmacological strategies suggested for prevention against $A F$ after coronary artery bypass grafting (CABG). The mechanism of atrial fibrillation involves two processes, focal triggers of enhanced automaticity and multiple wavelets of macro-reentry activation migrating across the atria ${ }^{4}$. Risk factors for developing atrial fibrillation include inflammation, oxidative stress, and atrial morphology Also ${ }^{2}$-blockers withdrawal, right coronary artery occlusion, reduced left ventricular function \& left ventricular hypertrophy are risk factors as well ${ }^{5}$. However the aging is a constant independent predictor for the incidence of $A F$ after $O P C A B$ 1. Although $A F$ in the early postoperative period is often sudden and self-limiting but can be continued for weeks and leads to increased morbidity, cardiac loss, embolic complications and the need for pacemaker ${ }^{6}$

Amiodarone acts as anti-arrhythmic drug mainly by blocking potassium $(\mathrm{K}+)$ channel and increasing the refractory period. It can be given both in oral \& intravenous form. Usual dosage varies from $600-1200 \mathrm{mg} /$ day as loading and 200$600 \mathrm{mg} /$ day as maintenance. It can cause bradycardia, QT prolongation, hypotension, AV conduction disturbances, peripheral vasodilation, hypo or hyperthyroidism, chemical pneumonitis \& pulmonary fibrosis, photosensitivity, ocular deposition, peripheral neuropathy etc. Most of these complications are dose dependent \& rare in short term low dose use ${ }^{7}$

Preoperative prescription of amiodarone is an interventional method which may reduce the incidence of $\mathrm{AF}$ after cardiac surgery ${ }^{6}$. Using low-dose intravenous or oral administration for 3-5 days before and after CABG surgery has reduced the incidence of $\mathrm{AF}^{3}$

Despite the high frequency of AF encountered during clinical practice, the concept of a proactive preventative measures became very appealing. Therefore the present study investigated the role of preoperative oral amiodarone in prevention of $\mathrm{AF}$ following $\mathrm{OPCAB}$.

\section{Materials and methods:}

It is an interventional study conducted in department of cardiac surgery, National Institute of Cardiovascular Disease (NICVD), Dhaka, Bangladesh during the period of 1st
February 2017 to 31 st January 2018 with the consent of ethical committee of this institute. By purposive sampling a total of 100 patients having sinus rhythm will undergo OPCAB were selected for the study. Among them 50 patients (GroupA) got amiodarone and 50 patients (Group-B) did not get amiodarone. Two (2) patients of group-A were excluded from the study due to conversion to on pump from off pump during operation. So, finally group A had 48 patients and group-B had 50 patients. Patients with sinus bradycardia (Heart rate below 60 beats $/ \mathrm{min}$ ), on other anti-arrhythmic drugs (Except 2-blockers), Redo, Urgent or Emergency CABG, patients with thyroid or liver dysfunction were excluded from the study. The objective of this study was to evaluate the effect of preoperative oral amiodarone in the prevention of atrial fibrillation for patients undergoing OPCAB. Also to evaluate incidence of postoperative AF after OPCAB in both groups and to compare the outcome between two groups. The patients under study were hospitalized at least 7 days before surgery. Preoperative ECG, serum electrolytes (e.g. potassium \& magnesium), thyroid function test, liver function test and echocardiogram were done in all patients under study. Amiodarone (Trade name: Pacet) was prescribed at a dosage of one tablet $(200 \mathrm{mg})$ three times daily $(600 \mathrm{mg} /$ day) 3 days prior to surgery. Other medical therapy was unchanged. Per operative occurrence of $\mathrm{AF}$ was assessed on operation theatre monitor. After OPCAB surgery, each patient was transferred to intensive care unit and then at $3 r d$ postoperative day was transferred to a step down or high dependency unit (HDU).

In intensive care unit (ICU) \& HDU, patients were evaluated by continuous ECG monitoring. Inotropic supports given to each patient up to 5 th postoperative day. Serum potassium \& magnesium were measured in every alternative day up to 5th postoperative day. An episode of atrial fibrillation was counted if it persisted for more than five minutes. Electrocardiography (ECG) with long lead tracing was done for all patients on the day of hospital discharge \& was recorded. At the end of study, patients' data was analyzed by SPSS software version 24.0. The numerical data obtained from the study was analyzed and significance of difference was estimated by using statistical methods. Continuous variables were expressed as mean values \pm standard deviation and compared using Student's t-test. Categorical variables were expressed as frequencies with percentages and compared using Chi-square test when and where appropriate. $P<0.05$ was considered significant.

\section{Result:}

Total 100 patients were selected for OPCAB. Among them 50 patients (Group A) got amiodarone and 50 patients (Group B) did not get amiodarone. 2 patients of group A were excluded from the study due to conversion to on pump from off pump during operation. So, finally group $A$ had 48 patients and group B had 50 patients. The findings of the study obtained from data analysis are presented below. 
Table-I

Comparison of Preoperative data between two groups $(N=98)$

\begin{tabular}{|c|c|c|c|}
\hline Preoperative variables & $\begin{array}{l}\text { Group A } \\
(\mathrm{n}=48) \\
\text { No. }(\%) \\
\end{array}$ & $\begin{array}{l}\text { Group B } \\
(n=50) \\
\text { No. }(\%)\end{array}$ & $P$ value \\
\hline Age(years) & $60.68 \pm 7.47$ & $60.06 \pm 6.16$ & - \\
\hline $\begin{array}{l}\text { Sex } \\
\quad \text { Male } \\
\text { Female }\end{array}$ & $\begin{array}{c}40(83.33 \%) \\
8(16.67 \%)\end{array}$ & $\begin{array}{c}45(90.0 \%) \\
5(10.0 \%)\end{array}$ & - \\
\hline $\begin{array}{l}\text { Pulse rate } \\
\text { Normal } \\
\text { Tachycardia }\end{array}$ & $\begin{array}{c}45(93.75 \%) \\
3(6.25 \%)\end{array}$ & $\begin{array}{c}48(96.0 \%) \\
2(4.0 \%)\end{array}$ & $0.646^{\mathrm{ns}}$ \\
\hline $\begin{array}{l}\text { Pulse rhythm } \\
\text { Regular } \\
\text { AF }\end{array}$ & $\begin{array}{c}48(100.0 \%) \\
0(0.0 \%)\end{array}$ & $\begin{array}{c}50(100.0 \%) \\
0(0.0 \%)\end{array}$ & - \\
\hline $\begin{array}{l}\text { ECG } \\
\qquad \begin{array}{l}\text { Normal } \\
\text { AF }\end{array}\end{array}$ & $\begin{array}{c}48(100.0 \%) \\
0(0.0 \%)\end{array}$ & $\begin{array}{c}50(100.0 \%) \\
0(0.0 \%)\end{array}$ & - \\
\hline $\begin{array}{ll} & \\
\text { TFT Euthyroid } \\
\text { Hypothyroid } \\
\text { Hyperthyroid }\end{array}$ & $\begin{array}{c}48(100.0 \%) \\
0(0.0 \%) \\
0(0.0 \%)\end{array}$ & $\begin{array}{c}50(100.0 \%) \\
0(0.0 \%) \\
0(0.0 \%)\end{array}$ & - \\
\hline $\begin{array}{l}\text { LFT } \\
\text { Normal } \\
\text { Abnormal }\end{array}$ & $\begin{array}{c}48(100.0 \%) \\
0(0.0 \%)\end{array}$ & $\begin{array}{c}50(100.0 \%) \\
0(0.0 \%)\end{array}$ & - \\
\hline $\begin{array}{l}\text { LVEF } \\
\quad \geq 50 \% \\
\quad<50 \%\end{array}$ & $\begin{array}{l}23(47.92 \%) \\
25(52.08 \%)\end{array}$ & $\begin{array}{l}20(40.0 \%) \\
30(60.0 \%)\end{array}$ & $0.545^{\mathrm{ns}}$ \\
\hline $\begin{array}{l}\text { Coronary artery involved } \\
\text { Single } \\
\text { Double vessel } \\
\text { Triple vessel } \\
\end{array}$ & $\begin{array}{c}4(8.33 \%) \\
16(31.25 \%) \\
28(60.42 \%) \\
\end{array}$ & $\begin{array}{c}3(6.0 \%) \\
17(34.0 \%) \\
30(60.0 \%) \\
\end{array}$ & $.565 \mathrm{~ns}$ \\
\hline
\end{tabular}

Table-II

Comparison of per-operative data between two groups $(N=98)$

\begin{tabular}{lccc}
\hline Per operative variables & $\begin{array}{c}\text { Group A } \\
(\mathrm{n}=48) \\
\text { No. }(\%)\end{array}$ & $\begin{array}{c}\text { Group B } \\
(\mathrm{n}=50) \\
\text { No. }(\%)\end{array}$ & P value \\
\hline $\begin{array}{l}\text { Occurrence of AF (monitor) } \\
\text { Yes }\end{array}$ & $10(20.83 \%)$ & $32(64.0 \%)$ & $<0.001^{*}$ \\
$\quad$ No & $38(79.17 \%)$ & $18(36.0 \%)$ & \\
Grafts given & & & \\
$\quad$ One & $9(18.75 \%)$ & $6(12.0 \%)$ & $0.629 \mathrm{~ns}$ \\
$\quad$ Two & $14(29.17 \%)$ & $17(34.0 \%)$ & \\
$\quad$ Three & $25(51.08 \%)$ & $27(54.0 \%)$ & \\
\hline
\end{tabular}

Figures in the parentheses indicate corresponding percentage; $n s=$ not significant, ${ }^{*}$ significant Chi-squared Test was done to analyze the data. 
Table-III

Comparison of immediate Postoperative data between two groups ( $N=98)$

\begin{tabular}{|c|c|c|c|}
\hline Postoperative variables & $\begin{array}{c}\text { Group A } \\
(\mathrm{n}=48) \\
\text { No. }(\%)\end{array}$ & $\begin{array}{c}\text { Group B } \\
(\mathrm{n}=50) \\
\text { No. }(\%)\end{array}$ & Pvalue \\
\hline \multicolumn{4}{|l|}{ Postoperative ECG } \\
\hline $\begin{array}{l}\text { Normal } \\
\text { AF }\end{array}$ & $\begin{array}{l}39(81.25 \%) \\
9(18.75 \%)\end{array}$ & $\begin{array}{l}19(38.0 \%) \\
31(62.0 \%)\end{array}$ & $<0.001^{*}$ \\
\hline \multicolumn{4}{|l|}{ Postoperative BP } \\
\hline Low & $7(14.6 \%)$ & $0(0.0 \%)$ & $<0.001^{*}$ \\
\hline $\begin{array}{l}\text { Normal } \\
\text { High }\end{array}$ & $\begin{array}{c}41(85.4 \%) \\
0(0.0 \%)\end{array}$ & $\begin{array}{l}36(72.0 \%) \\
14(28.0 \%)\end{array}$ & \\
\hline \multicolumn{4}{|c|}{$\begin{array}{l}\text { Postoperative use of anti-arrhythmic } \\
\text { drug }\end{array}$} \\
\hline $\begin{array}{l}\text { Yes } \\
\text { No }\end{array}$ & $\begin{array}{c}10(20.8 \%) \\
38(79.2 .0 \%)\end{array}$ & $\begin{array}{l}32(64.0 \%) \\
18(36.0 \%)\end{array}$ & $0.097^{\mathrm{ns}}$ \\
\hline
\end{tabular}

Figures in the parentheses indicate corresponding percentage; ns = not significant, *significant Chi-squared Test was done to analyze the data.

Table-IV

Postoperative ECG monitoring between two groups ( $N=98)$

\begin{tabular}{|c|c|c|c|}
\hline Postoperative ECG monitoring & $\begin{array}{c}\text { Group A } \\
(\mathrm{n}=48) \\
\text { No. }(\%) \\
\end{array}$ & $\begin{array}{c}\begin{array}{c}\text { Group B } \\
(n=50)\end{array} \\
\text { No. }(\%) \\
\end{array}$ & $P$ value \\
\hline Continuous ECG (ICU) in $1^{\text {st }} \mathrm{POD}$ & & & $0.006^{*}$ \\
\hline Normal & $39(81.2 \%)$ & $27(54.0 \%)$ & \\
\hline $\mathrm{AF}$ & $9(18.8 \%)$ & $23(46.0 \%)$ & \\
\hline Continuous ECG (ICU) in $2^{\text {nd }} P O D$ & & & $<0.001^{*}$ \\
\hline Normal & $38(79.2 \%)$ & $22(44.0 \%)$ & \\
\hline $\mathrm{AF}$ & $10(20.8 \%)$ & $28(56.0 \%)$ & \\
\hline ECG in HDU in $3^{\text {rd }} P O D$ & & & $<0.001^{*}$ \\
\hline Normal & $48(100.0 \%)$ & $30(60.0 \%)$ & \\
\hline $\mathrm{AF}$ & $0(0.0 \%)$ & $20(40.0 \%)$ & \\
\hline ECG in HDU in $4^{\text {th }} P O D$ & & & $0.063^{\mathrm{ns}}$ \\
\hline Normal & $48(100.0 \%)$ & $45(90.0 \%)$ & \\
\hline $\mathrm{AF}$ & $0(0.0 \%)$ & $5(10.0 \%)$ & \\
\hline ECG in HDU in $5^{\text {th }} P O D$ & & & $0.240^{\mathrm{ns}}$ \\
\hline Normal & $48(100.0 \%)$ & $50(100.0 \%)$ & \\
\hline $\mathrm{AF}$ & $0(0.0 \%)$ & $0(0.0 \%)$ & \\
\hline 12 Lead ECG on discharge & & & $0.068^{\text {ns }}$ \\
\hline Normal & $48(100.0 \%)$ & $50(100.0 \%)$ & \\
\hline $\mathrm{AF}$ & $0(0.0 \%)$ & $0(0.0 \%)$ & \\
\hline
\end{tabular}


In table 1 showed preoperative pulse rhythm, ECG, TFT, LFT were normal in all patients (100\%). Pulse rate were normal in $93.75 \%$ and $96 \%$ of group A and group B respectively, tachycardia in $6.25 \%$ and $4 \%$ of group $A$ and group B respectively. LVEF was $\geq 50 \%$ in $47.92 \%$ and $40 \%$ of group $A$ and group $B$ respectively and was $<50 \%$ in $52.08 \%$ and $60 \%$ of group $A$ and group $B$ respectively. Regarding coronary artery involvement, single vessel involvement was $8.33 \%$ and $6 \%$ in group $A$ and group $B$ respectively; Double vessel involvement was $31.25 \%$ and $34 \%$ in group A and group B respectively; Triple vessel involvement was $60.42 \%$ and $60 \%$ of group $A$ and group $B$ respectively. All the results were statistically not significant. $(\mathrm{P}>0.05)$.

In table-2, per-operatively one graft was given for $18.75 \%$ and $12 \%$ in group $A$ and group $B$ respectively; two grafts were given for $29.17 \%$ and $34 \%$ in group $A$ and group $B$ respectively; three grafts were given for $52.08 \%$ and $54 \%$ in group A and group B respectively. $P$ value was $>0.05$ which is statistically not significant.

Regarding AF occurrence (seen in monitor) per operatively, AF occurred $20.83 \%$ in group $A$ and $64 \%$ in group $B ; A F$ did not occur $79.17 \%$ in group $A$ and $36.0 \%$ in group $B$. The result was statistically significant $(P$ value $<0.05)$.

In table 3, postoperative pulse was normal in $81.25 \%$ and $38.0 \%$ of group Aand group B respectively; was AF in 18.75\% and $62.0 \%$ of group $A$ and group $B$ respectively. The result was statistically significant $(P$ value $<0.05)$.

Postoperative BP was low in $14.6 \%$ and $0.0 \%$ of group $A$ and group B respectively; was normal in $85.4 \%$ and $72.0 \%$ of group $A$ and group $B$ respectively and was high in $0.0 \%$ and $28.0 \%$ of group $A$ and group $B$ respectively. The result was statistically significant $(P$ value $<0.05)$.

Postoperative antiarrhythmic drugs were used in $20.8 \%$ and $64.0 \%$ of group A and group B respectively and not used in $79.2 \%$ and $36.0 \%$ of group $A$ and group $B$ respectively. The result was statistically not significant $(P$ value $>0.05)$.

In table 4 postoperative ECG in 1st POD was normal in $81.2 \%$ and $54.0 \%$ of group $A$ and group $B$ respectively and AF was present in $18.8 \%$ and $46.0 \%$ of group $A$ and group $B$ respectively. Postoperative ECG in 2nd POD was normal in $79.2 \%$ and $44.0 \%$ of group $A$ and group $B$ respectively and $A F$ was present in $20.8 \%$ and $56.0 \%$ of group $A$ and group $B$ respectively. Postoperative ECG in 3rd POD was normal in $100.0 \%$ and $60.0 \%$ of group $A$ and group $B$ respectively and $A F$ was present in $0.0 \%$ and $40.0 \%$ of group A and group $B$ respectively. On 3rd and 4th POD, ECG was normal in all patients of group A with no AF. But in group $B$, AF was present in $40 \%$ and $10 \%$ patient respectively. The results were statistically significant up to 3 rd POD ( $P$ value $<0.05)$.

Regarding 12 lead ECG on discharge, ECG was normal in all patients of both groups. The results were not statistically significant $(P$ value $\geq 0.05)$.

\section{Discussion:}

Ever since the establishment in 1981, National Institute of Cardiovascular Diseases (NICVD), Dhaka is performing a major role in cardiac surgery. This study was carried out in the department of cardiac surgery during the period of February, 2017 to January, 2018. As NICVD plays the central role in the field of cardiac surgery and off pump coronary artery bypass (OPCAB) in Bangladesh, study population was chosen from the institute. On average, around 300 CABG (both on pump and off pump) cases are performed at NICVD in every year ${ }^{8}$. Total 100 patients were selected for this study, divided into two groups. Out of them 50 patients (Group A) was intended to receive oral amiodarone before surgery and 50 patients (Group B) did not receive any amiodarone. But two cases were excluded from group $A$ due to conversion from off pump to on pump CABG. Finally total 98 cases were included under study (48 for Group A and 50 for Group B). The aim of this study was to determine whether preoperative oral amiodarone have any effect in the prevention of atrial fibrillation in patients undergone OPCAB.

The mean age of group A patients were $60.68 \pm 7.47$ years and group $B$ patients were $60.06 \pm 6.16$ years both ranging from 40 to 70 years. Analysis revealed that no statistically significant mean age difference was found between group A and group B patients ( $p>0.05)$. Homogenously both group had highest percentage (54.17\% for group $A$ and $50.0 \%$ for group B) of age group from 61-70 years.

In the study, majority of the patients were male in both groups. In group A and group B, 83.33\% and $90.0 \%$ were male and the rest $16.67 \%$ and $10.0 \%$ were female respectively. Homogenous distribution of sex was also present in both groups.

Preoperative pulse rhythm, ECG, TFT, LFT were normal in all patients (100\%). In group A and group B, pulse rate were normal in $93.75 \%$ and $96 \%$ and tachycardia in $6.25 \%$ and $4 \%$ respectively. Several studies also found preoperative normal heart rate, normal BP and normal liver function test $8,9,11$

In echocardiography, LVEF was e" $50 \%$ in $47.92 \%$ and $40 \%$ of group A and group B respectively and was $<50 \%$ in $52.08 \%$ and $60 \%$ of group $A$ and group $B$ respectively. Results were statistically not significant 
Regarding coronary artery involvement, triple vessels involvements were found in majority of the patients. Statistically, single vessel involvement was $8.33 \%$ and $6 \%$ in group A and group B respectively; Double vessel involvement was $31.25 \%$ and $34 \%$ in group $A$ and group $B$ respectively; Triple vessel involvement was $60.42 \%$ and $60 \%$ of group $A$ and group $B$ respectively. All the results were statistically not significant. Several studies also found majority of patient with triple vessels involvement followed by double vessels and single vesse ${ }^{2}$

Three grafts or more were given in majority of the patients. Per operatively, one graft was given for $18.75 \%$ and $12 \%$ in group $A$ and group $B$ respectively; two grafts were given for $29.17 \%$ and $34 \%$ in group $A$ and group $B$ respectively; three grafts were given for $52.08 \%$ and $54 \%$ in group A and group $B$ respectively. $P$ value was $>0.05$ which is statistically not significant. Onk and colleagues also found majority of patients $(60 \%)$ requiring three grafts 5,12

Per operatively, AF occurred more frequently in group $B$ than group A. AF occurred $20.83 \%$ in group $A$ and $64 \%$ in group $B$; AF did not occur $79.17 \%$ in group $A$ and $36.0 \%$ in group $B$. The result was statistically significant $(P$ value $<0.05)$.

Postoperative pulse was within normal limit in majority of the patients in both groups $(81.25 \%$ and $38.0 \%$ in group $A$ and group $B$ respectively. Postoperative $A F$ was high in group $B$ in comparison to group $A(18.75 \%$ and $36.0 \%$ in group $A$ and group $B$ respectively). The result was statistically significant $(P$ value $<0.05)$.

Group A showed hypotension more in comparison to group B postoperatively ( $14.58 \%$ and $0.0 \%$ of group $A$ and group $B$ respectively). Postoperative BP was normal in $85.42 \%$ and $72.0 \%$ of group $A$ and group $B$ respectively and was high in $0.0 \%$ and $28.0 \%$ of group $A$ and group $B$ respectively. The result was statistically significant $(P$ value $<0.05)$. Esmail with his colleagues found systolic BP $125 \pm 15 \mathrm{~mm}(\mathrm{Hg})$ and diastolic BP $76 \pm 10 \mathrm{~mm}(\mathrm{Hg})$ which were also within normal limit. 1,13

Dopamine was used in $93.8 \%$ and $100 \%$ of group $A$ and group $B$ respectively. In few patients $(6.0 \%$ and $18.0 \%$ of group $A$ and group $B$ respectively) dobutamine was used in exchange of dopamine after 1st postoperative day. But majority of the patient in both groups did not require dobutamine $(94.0 \%$ and $82.0 \%$ of group A and group B respectively). Some patients required adrenaline $(14.0 \%$ and $28.0 \%$ of group A and group B respectively) along with either dopamine or dobutamine. Noradrenaline was also used in $10.0 \%$ and $24.0 \%$ of group A and group B respectively with dopamine or dobutamine. No inotropic drugs were used in high dose. All the results were statistically not significant $(P$ value $>0.05$ ).

Postoperative AF was found in both groups in different proportions. Amiodarone (trade name: Pacet) was given in some patients of group A (18.8\%) up to 1st POD. But amiodarone was required up to 3rd POD in Group B (46.0\%). Postoperative ECG in 1st POD was normal in $81.2 \%$ and $54.0 \%$ of group A and group B respectively. Postoperative ECG in 2nd POD was normal in $79.2 \%$ and $44.0 \%$ of group $A$ and group $B$ respectively and AF was present in $20.8 \%$ and $56.0 \%$ of group $A$ and group $B$ respectively. Postoperative ECG in 3rd POD was normal in $100.0 \%$ and $60.0 \%$ of group $A$ and group $B$ respectively and AF was present in $0.0 \%$ and $40.0 \%$ of group $A$ and group $B$ respectively. On 3rd and 4th POD, ECG was normal in all patients of group A with no AF. But in group $B, A F$ was present in $40 \%$ and $10 \%$ patient respectively. The results were statistically significant up to 3rd POD (P value $<0.05$ ).

Both preoperative serum potassium and magnesium was normal in both group. Postoperatively, normal serum potassium and magnesium were found in majority of the patient. Mild hypokalemia and hypomagnesaemia was found more in group A than group B. This electrolyte imbalance may be due to excessive diuretics use and fluid and salt restriction. Though amiodarone itself can cause hypokalemia and hypomagnesaemia, but it is rare in low dose and short term use ${ }^{14}$.

In 1st POD, serum potassium was normal in $92.0 \%$ and $96.0 \%$ of group A and group B respectively; was low in $8.0 \%$ and $4.0 \%$ of group $A$ and group $B$ respectively. Electrolyte imbalances were corrected accordingly. In 3rd POD potassium was normal in $90.0 \%$ and $94.0 \%$ of group A and group $B$ respectively; was low in $10.0 \%$ and $6.0 \%$ of group $A$ and group $B$ respectively. In 5th POD potassium was normal in $90.0 \%$ and $96.0 \%$ of group $A$ and group $B$ respectively; was low in $10.0 \%$ and $4.0 \%$ of group $A$ and group $B$ respectively. All the results were statistically not significant ( $P$ value $>0.05$ ). Regarding serum magnesium, in 1st POD magnesium was normal in $94.0 \%$ and $98.0 \%$ of group $A$ and group $B$ respectively; was low in $6.0 \%$ and $2.0 \%$ of group $A$ and group $B$ respectively. In 3rd POD magnesium was normal in $92.0 \%$ and $96.0 \%$ of group $A$ and group $B$ respectively; was low in $8.0 \%$ and $4.0 \%$ of group $A$ and group $B$ respectively. In 5th POD magnesium was normal in $88.0 \%$ and $92.0 \%$ of group A and group B respectively; was low in $12.0 \%$ and $8.0 \%$ of group A and group $B$ respectively. All the results were statistically not significant $(P$ value $>0.05)$.

Postoperative pulse and BP were normal in majority of the groups. Few members of group A showed bradycardia and hypotension. But they were self-limiting and reverted to 
normal in short duration. Postoperatively, Pulse was low in $10.0 \%$ and $0.0 \%$ of group $A$ and group $B$ respectively; was normal in $62.0 \%$ and $64.0 \%$ of group $A$ and group $B$ respectively; was high in $28.0 \%$ and $36.0 \%$ of group $A$ and group $B$ respectively. Blood pressure was low in $6.0 \%$ and $0.0 \%$ of group $A$ and group $B$ respectively; was normal in $74.0 \%$ and $70.0 \%$ of group $A$ and group $B$ respectively; was high in $20.0 \%$ and $30.0 \%$ of group $A$ and group $B$ respectively. All the results were statistically not significant ( $P$ value $>0.05$ ). This observations were similar to the study of William $\mathrm{H}$, et al. ${ }^{15}$

There was no incidence of death in the study population

\section{Conclusion:}

In conclusion, our study results suggest that amiodarone administered according to this scheme reduces the onset of post-operative AF in a safe and well-tolerated manner. Thus, prophylactic treatment can be considered effective and should be used routinely for patients undergoing CABG in order to prevent AF thereby reduce the duration of hospital stay and costs.

Conflict of interest: We have no conflicts of interests to disclose.

\section{References:}

1. Esmail M, Nilufar D, Majid GE, Reza TNM, Abolfazl M. Prophylactic effect of amiodarone in atrial fibrillation after coronary artery bypass surgery; a double-blind randomized controlled clinical trail. J Cardiovasc Dis Res. 2015;6(1):12-17.

2. Habibollahi P, Jam S H, Vahdati S S, Baghi H M, Amiri M. Amiodaron in atrial fi brillation: post coronary artery bypass graft, World J Emerg Med. 2015;6(1): 54-59.

3. Alves RJ, Geovanini GR, Brito G de, Miguel GAS, Glauser VA, Nakiri K. Prevention of atrial fibrillation with moderate doses of amiodarone in the postoperative period of cardiac surgery is safe and effective in patients with high risk for developing this arrhythmia. Arq Bras Cardiol. 2007;89(1):22-27.

4. Kamali A, Sanatkar A, Sharifi M, Moshir E. Evaluation of amiodarone versus metoprolol in treating atrial fibrillation after coronary artery bypass grafting. Interv Med Appl Sci. 2017;9(2):51-55

5. Onk OA, Erkut B. Is the preoperative administration of amiodarone or metoprolol more effective in reducing atrial fibrillation: After coronary bypass surgery? Med (United States). 2015;94(41):1-8.

6. Bagshaw SM, Galbraith PD, Mitchell LB, Sauve R, Exner D V., Ghali WA. Prophylactic Amiodarone for Prevention of Atrial Fibrillation After Cardiac Surgery: A Meta-Analysis. Ann Thorac Surg. 2006;82(5): 1927-1937.

7. Bertram G. Katzung, MD, Basic \& Clinical Pharmacology, 12th edition, 2011, Lange Medical Publications, San Francisco USA.

8. Operation registrar book, (2015, 2016)National Institute of Cardiovascular Disease (NICVD) Dhaka, Bangladesh

9. Yagdi T, Nalbantgil S, Ayik F, et al. Amiodarone reduces the incidence of atrial fibrillation after coronary artery bypass grafting. J Thorac Cardiovasc Surg. 2003;125(6):1420-1425.

10. Treggiari-Venzi MM, Waeber JL, Perneger TV, Suter $\mathrm{PM}$, Adamec R, Romand JA. Intravenous amiodarone or magnesium sulphate is not cost-beneficial prophylaxis for atrial fibrillation after coronary artery bypass surgery. Br J Anaesth. 2000;85(5):690-695.

11. Koniari I, Apostolakis E, Rogkakou C, et al. Pharmacologic prophylaxis for atrial fibrillation following cardiac surgery: a systematic review $/$ 25-year-old woman with new-onset seizures. J Cardiothorac Surg. 2010;5(7):2243-2247.

12. Mcclure RS, Kaneko T, Tokmaji G, Mcclure RS, Kaneko T, Aranki SF. Management Strategies in Cardiac Surgery for Postoperative Atrial Fibrillation/ : Contemporary Prophylaxis and Futuristic Anticoagulant Possibilities. The Harvard community . 2017.

13. Esmail M, Nilufar D, Majid G, Reza TM. Prophylactic effect of amiodarone in atrial fibrillation after coronary artery bypass surgery J Cardiovasc Dis Res / ; 2010;6(1):1-6.

14. Hossein Almassi G, Schowalter T, Nicolosi AC, et al. Atrial fibrillation after cardiac surgery: A major morbid event? Ann Surg. 1997;226(4):501-513

15. Maisel WH, Rawn JD, Stevenson WG. Atrial Fibrillation after Cardiac Surger, Ann Intern Med.2001:1061-1073. 